\title{
RESENHAS
}

\section{CRÔNICAS DE EDUCAÇÃO}

Cecília Meireles

Rio de Janeiro, Nova Fronteira, 200 I, 252p.

Boa notícia nos chega com o centenário de nascimento de Cecília Meireles. Trata-se da publicação de sua obra em prosa, inclusive suas crônicas sobre educação, que irão surpreender as gerações que não puderam acompanhar a forte presença da autora nos jornais, entre as décadas de 30 e 60. O primeiro volume da série Crônicas de educação reúne textos muitas vezes inesperados, tanto para os que se acostumaram à Cecília poeta como para os que hoje se dedicam aos temas da educação. É provável que, finalmente retiradas dos jornais da época, essas crônicas passem a constituir estimulante material de pesquisa para a área educacional.

Encontra-se nesse primeiro volume a reunião de parte de suas crônicas jornalísticas publicadas entre 1930 e 1933 no Diário de Notícias do Rio de Janeiro. Neste jornal a autora manteve uma página diária sobre assuntos da educação, com entrevistas, notícias e a participação sistemática de colaboradores, entre os quais Fernando de Azevedo. A página continha ainda sua coluna diária, chamada "Comentário", na qual afirmava convicções e afiava sua requintada ironia. Escreveu, nesse período, mais de 700 crônicas.

A vida de Cecília Meireles esteve sempre ligada à educação. Foi professora, em todos os níveis, do primário ao superior. Participou ativamente do movimento reformista pela Educação Nova, escreveu diversos livros para crianças e criou a primeira biblioteca infantil do Rio de Janeiro, onde viveu, em 1937, o inusitado episódio da apreensão do volume de Tom Sawyer de Mark Twain, acusado de "comunista".

Com a Revolução de Trinta, eclodiu a luta entre liberais e conservadores no campo da educação. A educação pública e laica e a co-educação dos sexos estavam no coração do ideário progressista que Cecília Meireles defendia. Sua militância jornalística na defesa dos princípios do Manifesto dos pioneiros da educação nova foi incansável. Se o Manifesto, por ela assinado, foi o documento símbolo de uma geração de brasileiros que aplicou o melhor de suas inteligências e forças na luta pela democratização da educação, Cecília Meireles representava essa geração de maneira singular.

As crônicas de Cecília que compõem este volume são a comprovação de que generosidade e rigor podem andar juntas, desde que se tenha sabedoria para obter a rara combinação. Vemos nelas a abordagem simultânea, com excelentes resultados, de diversas dimensões da vida e dos fatos. Sentimos nos textos a presença da professora, da grande artista, da jornalista, da mãe, da militante de um movimento político social que acreditava na (ainda hoje) sedutora idéia da transformação pela educação. $\bigcirc$ espírito rigoroso de Cecília Meireles aparece na defesa desses princípios educativos. Critica sem pena e com grande mordacidade professores e autoridades. Não transige nem mesmo com os pais que, segundo ela, muitas vezes erram por preconceitos, ou por simples ignorância. Mas sua crítica não tem aquele tom, hoje tão comum entre educadores e intelectuais, do lamento e da queixa. Correspondendo a um momento histórico de grandes expectativas, sua crítica é otimista e trata a todos em condições de igualdade, como possíveis interlocutores, sem qualquer sentimento de conformismo ou comiseração diante da inciência e do obscurantismo.

Tem muitas palavras de incentivo e reconhecimento ao professorado, mas não baixa a guarda perante as resistências desse às mudanças. Dirige-se a todos: do presidente Getúlio Vargas àqueles pais que pedem ao professor que trate seu fiIho "com dureza". Fustiga o ministro Francisco Campos e seu "decretozinho do ensino religioso" e também as feministas vanguardistas reunidas em 
congresso, em 1931, que propõem medidas de apoio apenas "para as crianças pobres do sexo feminino". Antecipando-se a um feminismo sectário e empobrecedor, ela pergunta: "e os meninos?"

A escolha dos textos para compor a série Crônicas de Educação não deve ter sido tarefa fácil ao professor Leodegário A. de Azevedo Filho, que coordena a publicação da obra em prosa. Além das 700 crônicas da coluna "Comentário", há ainda as escritas no jornal $A$ Manhã, entre 194I e 1943, na coluna "Professores e estudantes". Serão ao todo cinco volumes apenas para o tema educação, afora diversos outros que somarão 23 volumes em prosa.

A série de educação está organizada em núcleos temáticos que são, neste primeiro volume, "Conceitos gerais de vida, educação, liberdade, beleza, cooperação e universalismo "e "Família, escola, infância e educação ". Com isso as crônicas mais diretamente políticas, em torno principalmente da Revolução de Trinta (sobre elas há interessante trabalho de Valéria Lamego, chamado A Farpa na Lirae publicado pela Editora Record), aparecerão provavelmente nos volumes seguintes. Tais crônicas são documentos de grande valor para a história da educação brasileira contendo inúmeras reflexões sobre os rumos da Revolução de Trinta e seus reflexos da área educacional. Para apresentar as Crônicas de Educação, o professor Azevedo Filho elaborou uma boa introdução que situa no tempo e na biografia de Cecília Meireles esse conjunto de textos.

Neste primeiro volume estão presentes reflexões sobre temas simples, do cotidiano, mas nem por isso desprovidos de surpresa e encanto. Atenta ao resto do mundo, Cecília nos fala de Gandhi, da Guerra Sino-Japonesa e nos lembra que "o coração de uma criança é sempre grande demais para abranger uma pátria só". Encontramos ainda reflexões sobre a situação do trabalho infantil e o conseqüente fracasso na escola, sobre a formalidade das festas escolares nas quais o que menos importa é a criança - como o relato sutilmente irônico do caso em que o convidado estrangeiro a uma dessas festas, no momento máxi- mo da solenidade, inicia o discurso, em sua língua, dizendo: "Crianças!...", mas elas haviam sido profilaticamente retiradas do recinto. Também o tema da relação da escola com a sociedade e mesmo com a comunidade que a cerca é forte e recorrente. A escola, diz Cecília Meireles, não é só para as crianças, "ela pode elevar, ao mesmo tempo, todo o ambiente social que rodeia cada geração (...) Por que recusar-se a ser o que pode ser na responsabilidade da civilização?"

Eram mesmo outros tempos. Tempos do chamado "otimismo pedagógico", de crença na possibilidade da transformação social intencional e certeira. Apesar de profunda conhecedora dos temas da educação, Cecília não falava como técnica. Mesmo sendo ainda jovem e estando envolvida em discussões explosivas, ia além de um discurso corporativo ou "partidário". Hoje suas crônicas continuam em grande parte atuais e são leitura obrigatória para os apreciadores da boa literatura e para todos que se dedicam a pensar e tentar entender os (des)caminhos da educação brasileira.

Ana Maria Villela Cavaliere

Faculdade de Educação da Universidade Federal do Rio de Janeiro anacavaliere@uol.com.br

\section{AVALIAÇÃO, CICLOS E PROMOÇÃO NA EDUCAÇÃO}

Creso Franco

Porto Alegre: Artmed, 200 I, 172p.

\section{Avaliar e repensar a escola}

É crescente o consenso nas sociedades contemporâneas sobre a necessidade de ampliar e aprofundar o debate sobre a qualidade e a eficiência da produção e da distribuição do conhecimento pelo sistema educacional, convertendo sua avaliação numa questão estratégica. No Brasil, com mais de $95 \%$ das crianças escolarizadas e situações de exclusão social persistentes, a avaliação da escola se constitui num problema ético e político 
de primeira grandeza para a construção de uma cidadania substantiva.

Nesse contexto, a coletânea Avaliação, ciclos e promoção na educação organizada por Creso Franco, constitui leitura praticamente obrigatória por sua pertinência e pela qualidade do debate que contém. Os diversos textos tomam como ponto de partida duas dimensões da discussão sobre avaliação na educação: o desenvolvimento recente de instrumentos de medida da qualidade do ensino oferecido nos diversos níveis do sistema educacional de um lado e, de outro, as repercussões da avaliação de desempenho acadêmico e das políticas de inclusão ensaiadas (ciclos, avaliação continuada, promoção automática etc.) sobre o fluxo escolar. Os diversos capítulos partem de pesquisas recentes em torno desses temas para problematizá-los de forma consistente e profunda. O livro é um convite a professores, pesquisadores, pais e decisores de políticas públicas para refletir sobre os resultados e as práticas de avaliação e a reforma do sistema educacional, tomando-os como uma oportunidade para repensar a educação e a escola hoje.

O percurso se abre com o texto de Franco e Bonamino "Iniciativas recentes de avaliação da qualidade da educação no Brasil", que traça um competente mapa das políticas de avaliação desenvolvidas na última década. Com base numa detalhada descrição das diferentes iniciativas recentes nessa área e de como estas se situam também no contexto internacional, o texto atualiza o leitor e aponta desafios técnicos e éticos a serem enfrentados tanto no campo da pesquisa e do desenvolvimento de instrumentos de avaliação como no campo da proposição e implantação de alternativas de política educacional.

Desde o início, como de certa forma se reflete e é confirmado no livro como um todo, transparece o posicionamento pela qualificação acadêmica e pelo balanceamento crítico e construtivo do debate, cujo potencial o livro testemunha com o exame cuidadoso de diferentes aspectos das práticas de avaliação em curso. Os capítulos seguintes encadeiam-se de modo instigante e consistente, conduzindo a discussão para questões como a eficiência da escola e dos diversos fatores que a influenciam.

Analisando as dificuldades inerentes à implantação dos ciclos na educação básica, o texto de Menga Lüdke "Evoluções em avaliação" retoma a questão do fracasso escolar e dos desafios da avaliação no processo educacional, enfatizando os limites e responsabilidades dos professores e gestores na implementação de possíveis mudanças na organização do trabalho da escola. A autora alerta para a importância da avaliação, no que ela denomina sua "função informativa", como insumo necessário para a efetiva qualificação da atividade docente. Segue-se interessante problematização das implicações da organização escolar em ciclos para a atividade docente e para as relações e os papéis dos profissionais envolvidos, bem como sobre as condições estruturais necessárias à boa consecução do processo escolar, ressaltando inclusive a necessidade de sua própria avaliação sistemática.

Nos dois textos subseqüentes, o debate avança com a investigação de experiências concretas de organização da escolaridade em ciclos. Se de um lado se enfatiza a necessidade de maior participação da sociedade e da adesão dos executores dessas políticas para possibilitar seu sucesso, por outro, mostra-se a complexidade das questões a enfrentar, particularmente no que se refere à formação e à identidade profissional dos docentes.

A contribuição de Mainardes sobre a organização da escolaridade em ciclos historia as experiências já realizadas no Brasil (São Paulo, Paraná, Rio de Janeiro, Santa Catarina, Minas Gerais e Goiás) desde a década de 60. Indo além de uma cuidadosa e detalhada descrição, o autor também apresenta as principais discussões que envolveram a formulação, a implantação e a avaliação (quando houve) dos frutos dessas políticas de correção do fluxo escolar, criticando a racionalidade economicista freqüentemente associada a seu fomento. Vale ressaltar ainda sua análise das repercussões dessas políticas quanto às concepções pedagógicas e aos desafios de gestão educacional. 
Como assinala Mainardes, e parecem reconhecer tanto os críticos como os proponentes de tais políticas, a capacitação dos profissionais e as condições de infra-estrutura das escolas são condições necessárias para possibilitar o êxito dessas iniciativas. A incursão histórica do autor mostra, entretanto, que além de tais condições não terem sido de fato preenchidas, pouco se tem usufruído das avaliações e pesquisas realizadas sobre a implantação das propostas. $\bigcirc$ autor reafirma ainda a necessária complementaridade entre a formulação e a realização de alternativas eficientes de inclusão escolar e a implantação de sistemas de supervisão e avaliação dos processos propostos, sob pena de arriscar obter resultados muito aquém dos esperados ou mesmo agravar os problemas que se pretendia resolver.

Focalizando um estudo de caso em São João del-Rey (Minas Gerais), Claudia Fernandes e Creso Franco mostram em detalhe, no artigo "Séries ou ciclos: o que acontece quando os professores escolhem?", os diferentes pontos de vista dos professores no que se refere à implantação dessas alternativas de "progressão continuada" nas redes públicas de ensino. Evidencia-se no estudo a diferenciação entre as perspectivas e práticas dos profissionais de acordo com sua formação, concepções e papéis profissionais na escola. Emerge então a imbricação entre formação docente e identidade profissional e sua repercussão nas concepções e práticas relativas à avaliação do desempenho dos alunos que acarretam diferentes reações às políticas propostas de redução da defasagem série-idade.

A análise das reações entre professores de $1^{\mathrm{a}} \mathrm{a} 4^{\mathrm{a}}$ ou de $5^{\mathrm{a}}$ a $8^{\mathrm{a}}$ séries do ensino fundamental, de aceitação ou rejeição das propostas de organização escolar em ciclos, respectivamente, indicou a correlação com sua identidade profissional, marcada por diferenças relevantes na formação inicial que se articulam com diferentes concepções da escola e de seu papel social. Nesse sentido, os autores concluem pela importância decisiva do acionamento de mecanismos de preparação abrangentes capazes de impactar tais identidades.
A reflexão proposta no livro vai assim equilibrando, em sucessivos e complementares níveis de abrangência e profundidade, os debates em torno da avaliação da escola, renovando a cada texto o convite para avançarmos no debate a partir dos dados de diferentes tipos de investigação. Os capítulos seguintes se debruçam sobre as práticas de avaliação do sistema educacional em vigor, particularmente sobre o Sistema Nacional de Avaliação da Educação Básica - SAEB -, apresentando desde a questão do conteúdo da educação escolar e sua seleção para referenciar as medidas que devem avaliar o desempenho escolar, até os desafios teóricos e metodológicos atuais das pesquisas nesse campo, trazendo ainda, nos dois últimos textos, resultados instigadores de pesquisas realizadas a partir dos dados gerados pelo SAEB.

O texto de Ortigão e Sztajn discute os dilemas presentes na elaboração das matrizes curriculares a partir dos quais são construídos os indicadores de avaliação de desempenho do SAEB. Inicialmente é traçado um histórico cuidadoso e extremamente instrutivo da elaboração dos instrumentos de medida de desempenho em matemática no SAEB desde seu lançamento em 1990, mostrando a complexidade do processo, permeado por diferentes influências na definição de o que deve ser avaliado e o que deve compor as "matrizes curriculares de referência" utilizadas para a confecção das questões das provas.

Tomando um dos tópicos do currículo de matemática, a teoria dos conjuntos, as autoras mostram os dilemas envolvidos na construção dos instrumentos e a dimensão política inerente às definições adotadas. Ortigão e Sztajn mostram como tais definições refletem também as concepções pedagógicas de grupos profissionais que delas participam, revelando o caráter prescritivo e não apenas descritivo da avaliação como política de estado. A partir de um caso concreto, as autoras introduzem o complexo debate sobre o que e o porquê se avalia. Retoma-se assim o problema do conteúdo da educação escolar e sobre quem define o "arbitrário cultural" expresso na seleção dos saberes presentes nos currículos escolares. 
O texto de Harvey Goldstein, "Modelos de realidade: novas abordagens para a compreensão de processos educacionais" aprofunda a discussão na "outra ponta" da questão, ou seja, mesmo encontrando-se consenso sobre os conteúdos e a qualidade do desempenho que se deseja avaliar, a realidade que se quer com isso compreender melhor apresenta-se na verdade muito mais complexa do que os instrumentos disponíveis para analisá-la. Goldstein mergulha então na questão dos modelos utilizados na análise dos resultados obtidos com a aplicação dos instrumentos de avaliação, cuja construção cheia de desafios políticos e pedagógicos testemunhamos no texto precedente. Sua reflexão sobre os limites e possibilidades dos modelos de pesquisa aplicados à avaliação educacional é especialmente relevante e atual, desmistificando os métodos quantitativos e o "mundo simplista das tabelas de classificação de resultados educacionais". Nessa perspectiva o autor denuncia o reducionismo das medidas baseadas numa sobrevalorização extremamente questionável da psicometria, pela Teoria da Resposta ao Item, cujas limitações e riscos procura mostrar.

Goldstein distingue entre a sofisticação maior ou menor da abordagem ou modelo descritivo adotado e a aparente complexidade técnica dos modelos estatísticos necessários para a manipulação dos dados obtidos. $\bigcirc$ autor tece então considerações instigantes sobre as razões possíveis para a hegemonia destas posições e propõe o desenvolvimento de modelos complexos para abordar realidades complexas - como é o caso da educação. Expondo ainda os resultados de trabalhos que vem realizando nessa perspectiva, em que se destaca a quantificação do chamado "valor agregado" pela escola, captado por modelos adequadamente formulados, Goldstein mostra sua fecundidade e desafia pesquisadores de diferentes áreas e formações para que rompam a polarização entre pesquisas quantitativas e qualitativas de maneira mais criativa e consoante com a complexidade do que se pretende compreender.

A contribuição de Jean-Claude Forquin, no capítulo "Evoluções recentes do debate sobre a escola, a cultura e as desigualdades", apresenta a riqueza das pesquisas recentes na França, que buscam desvelar a constelação de fatores intra e extra-escolares que influenciam a escolarização. Atualizando contribuições suas de textos anteriores, o autor descortina o estado da arte do debate atual sobre as desigualdades educacionais naquele país e nos brinda com sua qualificada contribuição sociológica sobre a escola e a cultura, que encontra eco em algumas das questões levantadas nos demais textos do livro, oriundas de pesquisas realizadas no Brasil.

O debate mais uma vez ganha em profundidade e assume outras facetas neste novo horizonte. Dentre elas destaca-se a atenção crescente para a influência de fatores como gênero, origem nacional ou étnica dos alunos e suas famílias, a localização da escola. Além disso, a questão das estratégias familiares na escolarização da prole tem merecido relevo nas pesquisas, articulando numa constelação os diversos fatores citados como a origem social e o contexto histórico, compondo o que se tem denominado a questão da "mobilização" em relação à escola. Tal constelação de determinações se expressa ainda na relação que os estudantes travam com o saber e o saber escolar em particular, como atestam os trabalhos de Lahire, Charlot, entre outros citados por Forquin, indicando novas perspectivas de compreensão das histórias singulares de sucesso ou fracasso escolar.

Os dois últimos capítulos realizam uma interessante incursão nos dados do SAEB 97, introduzindo-nos na riqueza das possibilidades de reflexão e intervenção a partir de sua análise. Em ambos os textos observa-se a saudável preocupação de mostrar ao leitor os caminhos metodológicos percorridos na busca de criar modelos explicativos para o desempenho dos alunos na área de matemática. O cuidadoso esforço dos autores, entretanto, mais do que satisfazer o leitor, revela o extenso caminho a percorrer para tornar mais consistente e produtiva a interlocução de pesquisadores mais especializados em investigações de caráter quantitativo com aqueles de maior experiência e conhecimento de métodos qualitativos. Concluí- 
mos a leitura com diversas perguntas curiosas e ainda mais convictos da riqueza dessa interlocução e das instigantes possibilidades de pesquisa que ela pode e deve abrir.

O texto de Soares, Cesar e Mambrini, "Determinantes de desempenho dos alunos do ensino básico brasileiro", busca dimensionar, a partir dos dados dos alunos da 8 a série em matemática que participaram do SAEB-97, a influência de diferentes fatores (escolas, professores e famílias) na construção das diferenças de desempenho observadas nas provas. Os autores nos trazem não apenas diversos resultados interessantes que motivam a continuidade do debate, mas também pistas para novas incursões de análise dos dados.

Dentre as conclusões cabe destacar a importância da maior ou menor regularidade nas trajetórias escolares, o sexo e a rede escolar freqüentada como fatores determinantes das diferenças de desempenho encontradas. Outro resultado que pode ser considerado fecundo, tanto do ponto de vista da pesquisa como da intervenção no sistema educacional, é a comprovação de que a escola (rede de ensino, condições de funcionamento etc.) é responsável por quase $40 \%$ da variabilidade do desempenho escolar. Ainda que a conclusão não seja exatamente nova do ponto de vista qualitativo, vê-la quantificada, no mínimo, realça a importância estratégica da intervenção nas condições de funcionamento do sistema escolar.

Assim como no texto anterior, no capítulo "A Escola brasileira faz diferença?" de Maria Eugênia F. Barbosa e Cristiano Fernandes, são analisados dados sobre a proficiência em matemática do SAEB-97, desta vez para alunos da 4 série da Região Sudeste do Brasil. Para enfrentar a complexidade da interação dos diversos fatores intervenientes na avaliação da eficácia da escola, os autores utilizam modelos de análise multinível, de forma que integre melhor a estrutura hierárquica dos dados (alunos, turmas e escolas) disponibilizados pelo SAEB.

Codificando em um número reduzido de fatores as diferentes variáveis potencialmente relacionadas às diferenças de desempenho encontradas, são construídas e testadas sete modelagens explicativas, considerando uma quantidade crescente de fatores. Ao analisar as diferentes variâncias encontradas, Barbosa e Fernandes chegam a conclusões que em boa medida reforçam e amplificam, no caso do $1^{\circ}$ segmento do $1^{\circ}$ grau, as traçadas no texto anterior. Além disso, a análise traz à tona outros aspectos importantes como o peso das características associadas ao professor è̀ sua interação com a turma, bem como a questão da motivação do aluno e a relação casa-escola, que nas pesquisas francesas se expressam no problema da mobilização em relação à escola, como havia apontado Forquin.

Concluindo, podemos dizer que o conjunto dos textos desta coletânea reafirma a importância da interação crítica entre a pesquisa e análise das práticas de avaliação tanto com os processos e instâncias de formação docente, como com os de elaboração de políticas públicas comprometidas com o fim da exclusão educacional. Além disso, as reflexões que suscita inspiram novas possibilidades de investigação desafiando os pesquisadores a renovar seus espaços de interlocução e produção entre as diversas áreas e com diferentes agentes sociais -, tornando mais fecunda sua contribuição para a construção de alternativas educacionais efetivamente democráticas e transformadoras.

Cynthia Paes de Carvalho Doutoranda pelo Departamento de Educação da Pontifícia Universidade Católica do Rio de Janeiro cynthiapcarvalho@uol.com.br 